\title{
Perceived risks and benefits of hippotherapy among parents of children currently engaged in or waiting for hippotherapy: A pilot study
}

\section{Running title: Perceived risks and benefits of hippotherapy}

Authors:

Léveillé, Audrey ${ }^{1,2,3,4}$

Occupational Therapist (MSc)

CISSS des Laurentides, Clinique externe de Psychiatrie

55, rue Saint-Joseph, $2^{\text {nd }}$ floor

Sainte-Thérèse (Québec) J7E 3J7

Canada

audrey.leveille@hotmail.com

Rochette, Annie ${ }^{1,2}$ (corresponding author)

Occupational Therapist, $\mathrm{PhD}$

School of Rehabilitation, Université de Montréal

C.P. 6128, Succursale Centre-Ville

Montréal (Québec) H3C 3J7

Canada

Tel.: 514-343-2192

Fax: 514-343-2105

annie.rochette@umontreal.ca

Mainville, Carolyne ${ }^{3}$

Occupational Therapist (MSc)

Clinique de réadaptation Carolyne Mainville

444, Avenue de l'Hôtel-Dieu

Sainte-Hyacinthe (Québec) J2S 5J5

Canada

cmainville@crmc.ca

1. Montreal University, Montreal, Quebec, Canada

2. Centre for Interdisciplinary Research in Rehabilitation of Greater Montreal (CRIR), Montreal, Quebec, Canada

3. Clinique de réadaptation Carolyne Mainville (CRCM), Saint-Hyacinthe, Quebec, Canada

4. Centre intégré de santé et de services sociaux des Laurentides, Point de services de Saint-Jérôme, Sainte-

Thérèse, Quebec, Canada

Total word count of the manuscript, including abstract, text, references, tables, annexe, and figure legends $=6152$ words

Keywords: hippotherapy, risks, benefits, children, qualitative study

\section{Funding source}

AR was supported by career awards from the Fonds de Recherche Québec - Santé in partnership with the Quebec Heart and Stroke Foundation. 
Perceived risks and benefits of hippotherapy among parents of children currently engaged in or waiting for hippotherapy: A pilot study

\section{$\underline{\text { ABSTRACT }}$}

Objective: Explore the perceived risks and benefits of hippotherapy among parents of children currently engaged in or waiting rehabilitation using hippotherapy. Method: Phenomenological qualitative exploratory pilot study. An interview guide validated by experts was used to conduct the interviews. Summaries were written to capture first impressions. One team member coded the transcripts and the coding was validated by the research team through discussion until consensus was reached. Results: The average age of the participants $(n=4)$ was $37.3 \pm 6.6$ years. The few risks they perceived related to physical injuries. Lack of knowledge of contraindications, lack of fear, minimization of risks and risk-attenuation factors also emerged as important themes. Benefits accounted for a large part of the content of the interviews and were grouped under 13 themes, including motor and postural control, enjoyment and the development of a special relationship. Conclusion: Minimization of the perceived risks compared to the numerous perceived benefits could create clinical issues such as the client putting self at risk of injuries (e.g. bites, falls, kicks) if not cautious enough or complications insufficiently prevented, which suggests the need to develop educational activities for an informed consent to this type of rehabilitation.

Keywords: hippotherapy, risks, benefits, children, qualitative study 


\section{INTRODUCTION}

Different approaches using horses for therapeutic purposes are increasingly popular with pediatric clients. According to the Canadian Therapeutic Riding Association (www.cantra.ca), three recognized approaches are associated with therapeutic riding in Canada: therapeutic, educational and recreational. The therapeutic approach includes therapeutic riding and hippotherapy. Therapeutic riding encompasses a variety of activities involving the use of horses for clients with disabilities and also instruction in riding techniques for riders with special needs. Hippotherapy is defined as a rehabilitation strategy used in the context of occupational, physical or speech therapy using the animal's three-dimensional movement and/or the affordances in the equine environment as treatment strategies to achieve various therapeutic objectives generally related to neuromotor function (AHA, 2010), but also to vestibular, proprioceptive, tactile and cognitive aspects (Heine, 1997). The American Hippotherapy Association (AHA) also reports beneficial effects on attention and emotions, sensory modulation and communication (AHA, 2010). Unlike therapeutic riding, hippotherapy is a treatment strategy exclusively utilized by state licensed health professionals such as occupational therapists, physiotherapists and speech language pathologists trained and accredited by the AHA (AHA, 2010; Heine, 1997; Violette \& Wilmarth, 2009). Hippotherapy can be used with a variety of clients with neuromusculoskeletal disorders including cerebral palsy (CP), autism spectrum disorders, developmental delay, genetic syndromes, learning difficulties, sensory integration disorders, language deficits, head trauma and stroke (AHA, 2010). The benefits of therapists incorporating hippotherapy into their treatment plans are being increasingly documented. A systematic review ( $=9$, PEDro score $\geq 3$ ) reported the impact of hippotherapy and therapeutic riding on gross motor function (Gross Motor Function Measure (GMFM), 66 or 88 items) in children diagnosed with CP with various neuromuscular conditions (Whalen \& Case-Smith, 2012). The benefits observed were even more 
significant in children aged 4 and over whose postural control, walking, running and jumping ability were limited. A meta-analysis ( $\mathrm{n}=8$, Critical Review Form score between 10.5 and 13) showed the beneficial impact of hippotherapy or therapeutic riding on postural control and balance in children with CP and simultaneously on activities of daily living (ADL), autonomy and quality of life. The group effect was positive (odds ratio 25.4, 95\% CI $4.4-148.5$, z=3.6) and a statistically significant association was reported in three of the articles examined (Zadnikar \& Kastrin, 2011).

Using horses poses a variety of risks. In any therapy treatment using equines there is always a risk of falling, which needs to be considered for informed decision-making since even welltrained horses can be unpredictable (AHA, 2006). More specifically, injuries that occur in recreational riding usually result from the rider falling (Hasler et al, 2011; Hawson, McLean, \& McGreevy, 2010; Jagodzinski \& DeMuri, 2005; Nelson \& Bixby-Hammett, 1992) while handlers and veterinarians are more likely to be injured by kicks. But what exactly are the risks associated with therapeutic riding approaches? The AHA issued a list of absolute contraindications to hippotherapy including mental health disorders compromising safety, acute herniated disk, type 2 Chiari malformation, atlantoaxial instability, coxarthrosis, children aged two years and under diagnosed with trisomy 21, symptomatic cauda equina syndrome and spinal instability (AHA, 2006). Severe hypotonia and Lobstein's disease may also be contra-indicated conditions while a risk of pressure sores may result from riding (Proust, Cottalorda, Alarmartine, \& Gautheron, 2004).

In addition, users' perceptions of the risks and benefits of hippotherapy have rarely been documented. An exploratory qualitative study (Debuse, Gibb, \& Chandler, 2009) looked at the effect of hippotherapy from the perspective of users or their family members with CP via 
individual interviews ( $\mathrm{n}=17)$ and focus groups. The participants were between 4 and 63 years of age. Normalization of muscle tone and improvements in postural control, walking, ADL, and feeling of self-efficacy, self-confidence and self-esteem were frequently reported. Also, a pilot study explored the impact of hippotherapy on the functional capacities of children $(n=4)$ with delayed motor development or motor deficits (Murphy, Kahn-D'Angelo, \& Gleason, 2008) using the Goal Attainment Scale (GAS) and parents’ perceptions via a self-administered questionnaire. The parents saw moderate improvements in performance on functional tasks. The GAS indicated variable effects for the targeted objectives (Kiresuk \& Sherman, 1968): a significant increase was noted for two children ( $\mathrm{p}=0.02$ and $\mathrm{p}=0.03$ ) while a significant decrease $(\mathrm{p}=0.02$ and $\mathrm{p}=0.009)$ was found for the other two participants. Disparities in the reported efficacy from these two perspectives were noted by the authors. But can therapeutic riding approaches involve additional risks or clinical issues such as aggravation or maintenance of neuromuscular conditions? Is it a real concern of users or their parents in comparison to parents and users before starting hippotherapy? Does it stay the same or evolve as the therapy progresses? This subject has not been explored in the scientific literature.

Study Objective

The objective of this study was to explore the risks and benefits of hippotherapy as perceived by parents of children currently engaged in or waiting for rehabilitation using hippotherapy.

\section{$\underline{\text { METHOD }}$}

\section{Study Design}

A phenomenological qualitative exploratory pilot design was chosen (Poupart et al, 1997) to examine the perceived risks and benefits of rehabilitation using hippotherapy by facilitating the emergence of unanticipated content. 


\section{$\underline{\text { Participants and Recruitment Procedures }}$}

This study looked at the perceptions of parents of children currently receiving or waiting for rehabilitation using hippotherapy. Hippotherapy sessions are offered by certified rehabilitation professionals (occupational therapist, physical therapist or speech language pathologist) as opposed to therapeutic riding offered by equine instructors and which are essentially adapted riding lessons. Because of recruitment problems, the sample was composed of three mothers of children actually receiving rehabilitation using hippotherapy and one father on the waiting list (ratio initially set at 2:2). This sample provided a wider variety of experience and was justified by the exploratory nature of the study. The inclusion criteria were to be parents of children between 1 and 10 years of age with a neurodevelopmental or neuromotor (poor muscle tone) condition who were receiving ( $>3$ months) or waiting for rehabilitation using hippotherapy. Individuals who could not speak French were excluded. Participants were recruited with the help of the rehabilitation clinic using leaflets and publications on the rehabilitation clinic Facebook page. Interviews lasting between 60 and 90 minutes were conducted at the rehabilitation clinic or at home. Approval from the Research Ethics Committee of the (Blinded) was obtained before screening the participants and collecting the data.

\section{$\underline{\text { Data Collection }}$}

An interview guide consisting of open-ended questions was developed using information from the literature and validated by the research team with complementary types of expertise (Appendix 1). There was no preliminary testing nor analysis of the interview guide as its purpose was to facilitate the unfolding of the interviews but also making sure to not be restrictive to its content. One interview was conducted with each participant. The interviews were audiotaped and 
transcribed in their entirety. Sociodemographic data (see Table 1) were collected to describe the sample.

\section{$\underline{\text { Data Analysis }}$}

Summaries were written to capture first impressions. A coding system validated through discussion by the research team was applied by first author. Each unit of meaning was assigned a code, then categorized to identify the main emerging themes in accordance with the study objective (Poupart et al, 1997) using QDA Miner to manage the data.

The Canadian Model of Occupational Performance and Engagement (CMOP-E) (Townsend \& Polatajko, 2013) was used to support the analysis and facilitated the organization of the main themes without necessarily limiting them. This occupational therapy model illustrates the interactions between persons, their environment and their occupations. Performance and engagement are influenced by the dynamic interplay between these factors.

\section{$\underline{\text { RESULTS }}$}

The sample consisted of three mothers of children currently receiving rehabilitation using hippotherapy and a father whose child was on the waiting list specifically to document different perspectives (Table 1). The participants were between 33 and 47 (average age $37.3 \pm 6.6$ years) and their children were between 3 and 6 (average age $4.4 \pm 1.4$ years). The children had one of the following diagnoses: encephalopathy, unspecified developmental delay or cerebellum dysfunction.

The analysis revealed five themes associated with the perceived risks (Table 2) while 13 emerging themes were related to the perceived benefits (Table 3). The reactions of the social environment encompassed three aspects. 


\section{Perceived Risks and Benefits}

The risks associated with hippotherapy by the parents did not emerge as a major concern. Some spontaneously mentioned the risk of physical injury from a fall. Only one participant waiting for rehabilitation using hippotherapy said that he viewed the risk of falling as slightly greater in riding than in hippotherapy. He was the only one to raise the risk of being bitten but considered the probability very low.. When asked about contra-indications, one participant whose child was waiting for rehabilitation using hippotherapy suggested a few contra-indications: severe allergies, taking medication, excessive fear of horses, surgery or a particular condition caused by cerebral palsy. As the interview went on, a progression was noted in this participant's answers, detailing potential clinical issues with more accuracy. This indicates that he was thinking about these aspects as he talked but had not dwelt on them very much before the interview. The reactions of the parents and children varied according to the situations experienced, but they all said they had no major fear reaction. Minimization of the risks led two participants to say that rehabilitation using hippotherapy did not necessarily involve a greater risk than other ADL or recreational activities, and that there were risks everywhere all the time. Five factors attenuated the perceived risks of rehabilitation using hippotherapy. For all the parents whose children were engaged in rehabilitation using hippotherapy, safety was not an issue. The presence of a health professional was reassuring and added medical value to the program. The numerous safety measures helped to reinforce the feeling of confidence, as did the structure and composition of the team. For the participant on the waiting list, the clinic's reputation attenuated the perceived risks. The presentation of the horses on the Website gave him an appreciation of the quality of the animals. Finally, certification of the clinicians was a concern for this participant, reinforcing his perception that rehabilitation using hippotherapy is a structured approach. 


\section{$\underline{\text { Physical Dimension }}$}

Concerning benefits, motor and postural control was the main theme emerging for the physical dimension. It did not take long for participants whose children were in the program to see improvements in neuromotor function. Two participants raised benefits with respect to strength and muscle tone. Balance was another theme mentioned by several participants and it had a significant impact in daily life (ability to crouch) for one child. On the other hand, one participant said that balance was not an intervention priority. Development or consolidation of gait pattern was another theme reported. One participant noted that a horse is particularly appropriate for this purpose, with the beneficial effect on spasticity of the stretching induced by sitting on a horse. Finally, two participants mentioned benefits with respect to fine motor skills.

\section{$\underline{\text { Affective Dimension }}$}

Increased motivation was noted in several children during rehabilitation using hippotherapy sessions, just from being in contact with the horse, which fostered optimal engagement without the need for constant outside encouragement. Enjoyment was also reported by all the participants whose children were having rehabilitation using hippotherapy. One participant talked about the pleasure her son felt simply at being told that he was going for rehabilitation with hippotherapy shortly. Finally, one participant mentioned her daughter's pride and feeling special vis-à-vis her friends at daycare due to the distinctive nature of the rehabilitation program using hippotherapy sessions.

\section{$\underline{\text { Cognitive Dimension }}$}

With respect to the cognitive dimension, one participant said the occupational therapist adapted to her child's abilities by using sounds to tell the horse to move forward, which facilitated the 
development of communication and language skills, especially in an environment conducive to communication. Understanding of instructions and learning were also facilitated.

\section{$\underline{\text { Social Environment }}$}

Rehabilitation using hippotherapy was sometimes associated with reactions from the social environment that could trigger envy from peers at the daycare. This had beneficial effects since it increased the value of this type of rehabilitation in the child's eyes. One participant explained that this rehabilitation method helped her child to detach from her, fostering integration at the daycare and contact with adults. The special relationship between horse and child was reported by all the parents whose children were currently having rehabilitation using hippotherapy; this relationship was expressed mainly by shows of affection and allowed the simultaneous integration of therapeutic objectives. This relationship induced one child to make a great effort to say the horse's name to his father. According to one participant, however, this special relationship did not seem specific to a particular horse or type of animal. One participant mentioned a gradual evolution in this relationship, which unfortunately suddenly deteriorated for no apparent reason. This means that as in any type of relationships, the way it evolves may be variable and depending on a number of influencing factors which were not specifically documented here.

\section{Personal Care}

None of the participants spontaneously mentioned any beneficial impacts of rehabilitation using hippotherapy on the domain of personal care. One participant said that this occupation domain was not an intervention priority while others would really like this rehabilitation approach to help develop those types of skills by impacting on other dimensions of the individual. 


\section{$\underline{\text { DISCUSSION }}$}

The objective of this study was to explore the risks and benefits of rehabilitation using hippotherapy from the perspective of parents of children currently receiving or waiting for this type of rehabilitation approach. The analysis of the data emerging from the interviews revealed some themes similar to those obtained by the authors of a qualitative study exploring the effects of rehabilitation using hippotherapy on people diagnosed with CP from the perspective of users or their parents (Debuse, Gibb, \& Chandler, 2009). As in the present case, the main effects of rehabilitation using hippotherapy reported by the participants included normalization of muscle tone, improved trunk control and improved walking skills (gait pattern). Unlike this study, the themes emerging from the data analysis did not include any significant benefits with respect to ADL. In addition, although some emerging themes were in the affective dimension, the findings of Debuse and colleagues (2009) were more a matter of improvements in self-confidence, selfesteem and the feeling of self-efficacy. The present study confirmed some of the results obtained in that article and simultaneously provided new data concerning parents' perceptions of rehabilitation using hippotherapy, and especially the perceived risks, which were not a major concern for them. In fact, minimization of the perceived risks was noted compared to the numerous perceived benefits. Despite some similarities in the themes reported by the participants, their comments were too heterogeneous for saturation of the themes to be achieved. This is not surprising given the small sample size and it would be valuable to replicate this pilot study with a larger sample to be able to achieve saturation.

The organization of the different themes that emerged based on the CMOP-E showed that the main benefits perceived by the parents mostly fell under the different personal dimensions. Emerging evidence is increasingly documenting the benefits of rehabilitation using hippotherapy 
for functional skills (Murphy, Kahn-D'Angelo, \& Gleason, 2008; Zadnikar \& Kastrin, 2011). It is interesting to note that some authors found disparities between the impact of rehabilitation using hippotherapy on functional skills from the parents' perspective compared to the results obtained with a measuring instrument used by the professionals (Goal Attainment Scale) (Murphy, Kahn-D'Angelo, \& Gleason, 2008). The parents mentioned overall moderate improvements in the performance of functional tasks and activities at home stemming from the therapy sessions (conducted by PT, OT or SLP) using equines and their movement, including walking, dressing and vocalization frequency, while significant improvements were observed in some children on the GAS results. These authors highlighted the disparities in the reported efficacy from these two perspectives, suggesting the need for future research to further explore consistency in the results from quantitative studies compared to qualitative studies.

The scientific literature contains very little documentation concerning the risks associated with therapeutic riding approaches in general. The participants knew little about contra-indications for rehabilitation using hippotherapy. Similarly, aggravation or maintenance of the users' neuromuscular conditions was not spontaneously mentioned as a concern by parents with children receiving or waiting for this type of rehabilitation approach. In addition to this lack of knowledge of the risks associated with using a horse in rehabilitation, they had difficulty correctly distinguishing between the characteristics of each approach i.e. rehabilitation using hippotherapy as compared to therapeutic riding. The analysis of the data obtained in this study showed that some participants had limited ability to distinguish rehabilitation using hippotherapy using the movement of the horses with specific therapeutic objectives and offered by a certified occupational therapist, physical therapist or speech language pathologists as part of a rehabilitation program compared to therapeutic riding approaches which are offered by an equine 
instructor and are essentially adapted riding lessons. This lack of knowledge could accentuate the risks in each of these approaches. According to Mainville and colleagues (2013), rehabilitation using hippotherapy has the advantage of meeting the needs of clients who have more severe impairments and specific rehabilitation objectives compared to the other approaches. These authors also mentioned confusion in the terminology between the different therapeutic riding approaches. This confusion appears to be present in users, referring agencies and sometimes even in the professionals/instructors offering therapeutic riding services. Indeed, as hippotherapy is not yet, in most countries, a reserved act by rehabilitation professionals, equine instructors could advertise their services without making a clear distinction between these approaches. This limited knowledge may increase risks of injuries as the supervision is different, as are the aims and thus the targeted clientele. An example of clinical issues which could arise from this unclear distinction is an aggravation or maintenance of the physical dimensions if the inappropriate approach is offered by the inappropriate professionals/instructors.. More specifically, Mainville and colleagues further noted that this lack of knowledge stems partly from insufficient understanding of the impact of the transmission of the horse's movement on the rider and limited knowledge about different neurodevelopmental conditions, spasticity, tonus and primitive reflexes. However, much of the issue stems probably from insufficient education among clients and from unclear or misleading marketing, websites and explanations given by professionals/instructors. These risks have still not yet been documented with evidence-based data, which justifies the need to develop guidelines to ensure that programs and referrals are safe and tailored to users' needs. In this regard, Mainville and colleagues noted the importance of developing a continuum between the different approaches according to the type of client. It should be noted as well that training certification and licensure of the professional providing the 
various types of service involving equines and how they differ fundamentally from each other should be addressed. Therapeutic riding is an adapted sport, not a therapy treatment and should be described and marketed as such whereas rehabilitation professionals using equine is therapy. Therefore, another priority is the transfer of knowledge to the general public, service users, referring agencies and health professionals/instructors to ensure effective and appropriate application of knowledge.

\section{$\underline{\text { Study Strengths and Limitations }}$}

This innovative exploratory pilot study generated some preliminary results concerning parents' perceptions of the risks and benefits they associate with rehabilitation using hippotherapy. The results clarify perceptions of this rehabilitation method. The qualitative design allowed us to examine a phenomenon that has received little attention to date since it included participants whose children are currently receiving or waiting for rehabilitation using hippotherapy. However, the exploratory nature of this pilot study and sample size limit the generalizability of the data to a broader population and other populations, especially since only one participant waiting for rehabilitation using hippotherapy could be recruited to participate in this study. As this pilot study proved to be feasible and the results are meaningful, we would recommend that the methods be replicated with a larger sample to also enable researchers to document the presence of correlations between the results and the participants' sociodemographic characteristics. Finally, since the participants were recruited on a voluntary basis, those who were willing to be interviewed may have had a favorable view of rehabilitation using hippotherapy given their interest in this rehabilitation method, which could have introduced a participation bias. 


\section{CONCLUSION}

In general most of the participants correctly identified the benefits of rehabilitation using hippotherapy, which are being increasingly documented in the scientific literature. However, minimization of the perceived risks compared to the perceived benefits, in addition to a lack of knowledge of the distinctions between the approaches using a horse, may create clinical issues in some populations looking for a treatment (thus wanting rehabilitation using hippotherapy) but who do not receive one if they get therapeutic riding. The results of this pilot study suggest the need to develop educational activities to clarify the different approaches using a horse and increase users' understanding of the risks and potential clinical issues associated with each of these approaches.

\section{$\underline{\text { Declaration of Interest }}$}

The authors declare they have no conflict of interest. 


\section{$\underline{\text { REFERENCES }}$}

AHA 2006 Hippotherapy treatment principles Level 1.

AHA 2010 American Hippotherapy Association. http://www.americanhippotherapyassociation.org/

Debuse D, Gibb C, Chandler C 2009 Effects of hippotherapy on people with cerebral palsy from the users' perspective: a qualitative study. Physiother Theory Pract, 25: 174-192.

Hasler RM, Gyssler L, Benneker L, Martinolli L, Schotzau A, Zimmermann H, Exadaktylos AK 2011 Protective and risk factors in amateur equestrians and description of injury patterns: A retrospective data analysis and a case - control survey. J Trauma Manag Outcomes, 5: 4.

Hawson LA, McLean AN, McGreevy PD 2010 The roles of equine ethology and applied learning theory in horse-related humain injuries. Journal of Veterinary Behavior, Clinical Applications and Research: 324-338.

Heine B 1997 Introduction to Hippotherapy. NARHA Strides magazine, 3.

Jagodzinski T, DeMuri GP 2005 Horse-related injuries in children: a review. WMJ, 104: 50-54.

Kiresuk T, Sherman R 1968 Goal attainment scaling: a general method for evaluating comprehensive community mental health program. Community Ment Health J, 4: 443-453.

Mainville C, Briand C, Leduc N. (2013). Modélisation et analyse des interventions d'équitation thérapeutique utilisées à des fins de réadaptation. (Mémoire de maîtrise inédit), Université de Montréal, Montréal. http://hdl.handle.net/1866/10592

Murphy D, Kahn-D'Angelo L, Gleason J 2008 The effect of hippotherapy on functional outcomes for children with disabilities: a pilot study. Pediatr Phys Ther, 20: 264-270.

Nelson DE, Bixby-Hammett D 1992 Equestrian injuries in children and young adults. American Journal of Diseases of Children, 146: 611-614.

Poupart J, Deslauriers J-P, Groulx LH, Laperrière A, Mayer R, Pires A 1997 La recherche qualitative: enjeux épistémiologiques et méthodologiques, Montréal: Gaëtan Morin.

Proust P, Cottalorda J, Alarmartine E, Gautheron V 2004 Apports de l'hippothérapie dans la prise en charge du handicap. Journal de Réadaptation Médicale, 24: 86-89.

Townsend EA, Polatajko HJ 2013 Faciliter l'occupation: l'avancement d'une vision de l'ergothérapie en matière de santé, bien-être et justice à travers l'occupation. Canada: ON, Publications: ACE.

Violette K, Wilmarth MA. (2009). Hippotherapy: A Therapeutic Treatment Strategy. Today in PT.com. http://www.todayinpt.com/ce/PT09/CoursePage/ 
Whalen CN, Case-Smith J 2012 Therapeutic effects of horseback riding therapy on gross motor function in children with cerebral palsy: a systematic review. Phys Occup Ther Pediatr 32: 229242

Zadnikar M, Kastrin A 2011 Effects of hippotherapy and therapeutic horseback riding on postural control or balance in children with cerebral palsy: a meta-analysis. Dev Med Child Neurol, 53: 684-691. 
Table 1. Participants’ characteristics

\begin{tabular}{|c|c|c|c|c|c|}
\hline Participant & Age & Sex & Schooling & $\begin{array}{l}\text { Gross annual family } \\
\text { income }\end{array}$ & $\begin{array}{l}\text { Child regularly followed by } \\
\text { the following }\end{array}$ \\
\hline P1 & 35 & $\mathrm{~F}$ & $\begin{array}{l}\text { Master's } \\
\text { degree }\end{array}$ & $>\$ 81,000$ & $\begin{array}{l}\text { Occupational therapy, } \\
\text { physiotherapy, speech therapy }\end{array}$ \\
\hline $\mathrm{P} 2$ & 33 & $\mathrm{~F}$ & $\begin{array}{l}\text { Vocational } \\
\text { diploma }\end{array}$ & $\begin{array}{l}\text { Between } \$ 61,000 \text { and } \\
\$ 80,000\end{array}$ & $\begin{array}{l}\text { Occupational therapy, } \\
\text { physiotherapy, speech therapy }\end{array}$ \\
\hline P3 & 34 & $\mathrm{~F}$ & $\begin{array}{l}\text { Bachelor's } \\
\text { degree }\end{array}$ & $>\$ 81,000$ & $\begin{array}{l}\text { Occupational therapy and } \\
\text { physiotherapy }\end{array}$ \\
\hline $\mathrm{P} 4$ & 47 & M & $\begin{array}{l}\text { Bachelor's } \\
\text { degree }\end{array}$ & $>\$ 81,000$ & $\begin{array}{l}\text { Physiotherapy and speech } \\
\text { therapy }\end{array}$ \\
\hline
\end{tabular}




\begin{tabular}{|c|c|}
\hline Themes & Extracts from the transcripts \\
\hline - Risk of injury & $\begin{array}{l}\text { P1: Some risk that she'll fall, I guess... } \\
\text { P4: It's the risk of falls, mainly. } \\
\text { P4: Certainly... there's more risk of falling from a horse if you ride more... I } \\
\text { don't know. } \\
\text { P4: I don't think he'll get bitten or anything like that, but... }\end{array}$ \\
\hline $\begin{array}{l}\text { Lack of knowledge of } \\
\text { clinical issues and } \\
\text { contra-indications }\end{array}$ & $\begin{array}{l}\text { P4: But there might be stupid things like allergies or stuff like that. [...] } \\
\text { Someone, er, who has to take medications. [... ...and it's not specific to } \\
\text { hippotherapy, it could be zootherapy or something else... [...] At some point, if } \\
\text { people, who sometimes, er, who are afraid of animals. Again, it could be one } \\
\text { way of, er, controlling it a bit... But I'm not talking just about a small fear, er, } \\
\text { because I don't know the unknown but, since some people have phobias, for } \\
\text { example. [...] There's nothing in it that bothers me... [...] Or if for example, he } \\
\text { had just had an operation, er, I don't know... Often, in cerebral palsy, hip } \\
\text { problems, for example, things like that. I imagine that the position for some } \\
\text { people could be more problematic. } \\
\text { P4: We don't want to make his case worse either. }\end{array}$ \\
\hline $\begin{array}{l}\text { - No major fear reaction } \\
\text { among parents or their } \\
\text { children }\end{array}$ & $\begin{array}{l}\text { P1: [...] it happened sometimes that she didn't look too sure. But that's not } \\
\text { every time. [...] After that one time she ended up on the side, she had his brush } \\
\text { and was occupied, it's as if, I don't know, she wasn't thinking about it any } \\
\text { more or... [...] It surprised her another time when Mousse sort of shrieked... } \\
\text { [...] I was like 'wooahhh'... But not enough to be really afraid... [...] She } \\
\text { wasn't all upset, she was just like 'woahhh’! [...] } \\
\text { P3: [...] I jumped but I... compared to him [the horse]. } \\
\text { P3: [No reaction?] No! No, well, not as far as I remember in any case. So, er, I } \\
\text { imagine that it had been okay... } \\
\text { P4: But I have to admit it, I don't know... Or that [child's name] it wasn't } \\
\text { working, he was afraid of the horse, er, he didn't want to go anymore but I } \\
\text { don't really know or no matter. There won't necessarily be overinvestment if } \\
\text { we see that... it doesn't make sense. }\end{array}$ \\
\hline - Minimization of the risk & $\begin{array}{l}\text { P1: ...but there are risks in everything! }[\ldots] \text { We go to the pool, there's a risk } \\
\text { she'll swallow water, we go... [...] Even at home there's a tree that could fall } \\
\text { on the house. } \\
\text { P4: ...there's always a risk, but there's a risk in everything. There's a risk } \\
\text { crossing the street. }\end{array}$ \\
\hline - Risk-attenuation factors & $\begin{array}{l}\text { P2: Safety is really... I don't have anything to say about that. } \\
\text { P3: When I come here, I am totally confident. } \\
\text { P1: It's that, for me, knowing she is with an occupational therapist I feel } \\
\text { better... } \\
\text { P4: [...] but all the time you have at least one occupational therapist. [...] So } \\
\text { that reassures me a lot, in fact, regarding the risks. } \\
\text { P4: [Do you think in fact that you have more confidence in the hippotherapy } \\
\text { program compared to therapeutic riding?] Well... well, I'd say yes because it's } \\
\text { really more medical... And it's more, er... I'd say based on studies or er... [...] } \\
\text { it's more, er... health specialists that are on it... } \\
\text { P1: For myself, I consider... I think they're great, er, safe. I see all the safety } \\
\text { measures and they pay close attention... } \\
\text { P3: Everyone reacted really fast, and... as if nothing happened. }\end{array}$ \\
\hline
\end{tabular}


P2: ...there are three of them. There's always one with the horse, one for the accessories, the activities, and there's the occupational therapist. So he's never alone. He's never, er... they are always close by.

P4: So, now, basically, three is the minimum. [...] And I imagine that if they do that, it's a proven formula.

P4: [...] I have more faith in this rehabilitation clinic. They are more known and recognized for that versus someone else whose 'background' I don't necessarily know, so, er, I cannot judge but, at the beginning I won't take any chances and then I'll see.

P4: ...I saw, it was reassuring on the Website it said: this is our whole stable. And this horse, see his nature, calmer. [...] And, er... well, many are called but few are chosen, so I said to myself: it's like the elite.

P4: And, it's, er, certifications also for... concerning hippotherapy. [...] Hippotherapy Canada or something like that... [...] So basically, they are all... it's not thrown together, er, or something like that...You say to yourself, it's okay, I see a certain structure... 


\begin{tabular}{|c|c|}
\hline Themes & Extracts from the transcripts \\
\hline $\begin{array}{l}\text { Physical dimension: } \\
\text { - Motor and postural } \\
\text { control }\end{array}$ & $\begin{array}{l}\text { P1: ...after that, I think it's good for her also to have... different ways to work } \\
\text { on her balance, her trunk and control of her head, not always in the same } \\
\text { contexts. So I think it's fun that she's working on it another way. } \\
\text { P1: Yep, she [child] lifts her arms to touch the horse... [...] She couldn't do that } \\
\text { before. } \\
\text { P1: Her control of her head is much, much better. } \\
\text { P1: And she holds herself straighter in general. [...] At times she tended to be } \\
\text { really bent over. } \\
\text { P3: [...] I find she has better postural control. }\end{array}$ \\
\hline $\begin{array}{l}\text { - Strength and postural } \\
\text { tonus }\end{array}$ & $\begin{array}{l}\text { P2: He [the child] is more solid. } \\
\text { P2: He is much stronger also... } \\
\text { P3: Really her muscle tone. [...] ...I feel that she [child] has really gotten } \\
\text { stronger... she has learned to use... [her muscles]. Yes, properly because she } \\
\text { used to stretch forward all the time. }\end{array}$ \\
\hline - Balance & $\begin{array}{l}\text { P1: I think that it's good for her to have different ways to work on her balance. } \\
\text { P2: There's no question that it works for [child's name] his balance a lot. [...] } \\
\text { There's no question that his balance, er... It used to make him fall a lot, really a } \\
\text { lot... [...] He stumbled into everything, everything. [...] And now, er... He no } \\
\text { longer bends over. [...] He crouches down, he didn't do that before. } \\
\text { P4: In fact, balance, er, yes, I was aware, I was perhaps less, er... that he has a } \\
\text { balance problem. It's not his strength. It's [occupational therapist's name] who } \\
\text { told me: yes, it's one of the known, recognized and studied benefits. It's been } \\
\text { shown scientifically. So, er, I said ah, that is helpful, it was one of his } \\
\text { weaknesses, but it wasn't my... [...] It wasn't bad but it wasn't a priority either. }\end{array}$ \\
\hline - Gait pattern & $\begin{array}{l}\text { P1: But I heard that it was good for the hips because when the horse walks it sort } \\
\text { of imitates the movement of the hips and weight transfer; that's it, the weight } \\
\text { transfer. } \\
\text { P4: But at the same time showing him how to walk with a good pattern... In that } \\
\text { regard I was convinced that another human being or a machine would never be } \\
\text { as effective [as a horse]. [...] They [Websites] said there was sort of a... a } \\
\text { correlation between the two gaits: between how a human walks and how a horse } \\
\text { walks. } \\
\text { P4: Right, hippotherapy and spasticity... yes, it creates stretches because... [...] } \\
\text { I forget all the time... the internal adductors }[\ldots] \text { that make... that makes } \\
\text { walking a scissor movement, things like that. [...] I imagine when you do that } \\
\text { on each side of a horse... it will create a type of stretching too. [...] So, er... it } \\
\text { can't hurt. }\end{array}$ \\
\hline - Fine motor skills & $\begin{array}{l}\text { P1: I'm also happy because at the beginning [occupational therapist's name] } \\
\text { worked on fine motor skills. There are no other therapists who work on fine } \\
\text { motor skills [in the other regular programs]. }\end{array}$ \\
\hline $\begin{array}{c}\text { Affective dimension: } \\
\qquad \quad \text { Motivation }\end{array}$ & $\begin{array}{l}\text { P2: In hippotherapy it's more, er... There's less motivation to do it, I think... } \\
{[\ldots] \text { And there are less refusals or... sometimes... he whines less }[\ldots] \text { than in }} \\
\text { normal therapy. }\end{array}$ \\
\hline
\end{tabular}




\begin{tabular}{|c|c|}
\hline $\begin{array}{l}\text { - Pride and feeling } \\
\text { special }\end{array}$ & $\begin{array}{l}\text { P4: It's definitely more motivating, probably, for a child to be on a horse than } \\
\text { just be on a ball, for example. [...] It takes more time to get fed up on a horse, I } \\
\text { think. } \\
\text { P1: ... but I find that with the horse it's that... she is happy to come see her horse } \\
\text { [...]. Because that's it, I find that she doesn't come just to go riding. She comes } \\
\text { to play. So she... Yep, I'd say that she has a lot of fun. } \\
\text { P2: Ah, he is overexcited! Really! [...] Very excited! [...] Sometimes we'd tell } \\
\text { him the night before that the next day [he had a hippotherapy session]... He } \\
\text { wouldn't sleep at night... [...] He was too excited! [...] Really happy... [...] He } \\
\text { looks forward to it, oh yes, yes, yes. } \\
\text { P1: And I find that for her, it gives her a little something special. She goes to } \\
\text { daycare and she does that [hippotherapy], but the others don't do that because } \\
\text { the others are normal, they don't have anything. [...] So I find that it is } \\
\text { something special for her. }\end{array}$ \\
\hline $\begin{array}{l}\text { Cognitive dimension: } \\
\qquad \quad \text { Communication and } \\
\\
\text { language skills }\end{array}$ & $\begin{array}{l}\text { P1: And I find that it's fun also because I told [occupational therapist's name]: } \\
\text { 'she makes more sounds, all that' [occupational therapist's name] she can } \\
\text { incorporate such as: '[child's name] today she made sounds to get her horse to } \\
\text { move forward'. } \\
\text { P3: It's sure that... because she is really in the language prerequisites. [...] So } \\
\text { it's fun because in hippotherapy, I saw at the beginning } 1,2,3 \text { [then taps the } \\
\text { helper's hand to get the horse to move forward]... } \\
\text { P2: It definitely motivates him a lot to talk. [...] The environment is conducive } \\
\text { to that also. } \\
\text { P2: ...that [hippotherapy] helped him develop his colors. [...] It's quite a bit } \\
\text { better, he has started to say his colors. } \\
\text { P3: [To get her horse to move forward], she would put her hand in the person's } \\
\text { hand, so I found she could understand something, she understood what was } \\
\text { expected of her, and... [...] responded to it. } \\
\text { P2: ...than in normal therapy; he also understands quicker, I think. }\end{array}$ \\
\hline $\begin{array}{l}\text { Social environment } \\
\bullet \quad \text { Envy from peers }\end{array}$ & $\begin{array}{l}\text { P1: ...I heard one time [at daycare]: 'Me too, mommy, I'd like to go riding like } \\
\text { [child's name], she goes riding.' [...] I think that gives her something that the } \\
\text { others would like to have. [...] Whereas often... [...] it's the opposite, but in } \\
\text { that she has something more desired. [...] I also think that the fact that her } \\
\text { friends find it interesting, I think that increases its value for her. } \\
\text { P3: She managed to detach from me because the early sessions, it was really, I } \\
\text { would walk beside the horse. [...] At some point I managed to move away and } \\
\text { she was able to work even though I wasn't there. The fact that she accepted to } \\
\text { detach from me, er... [...] I think it's really the hippotherapy. [...] Because } \\
\text { otherwise all the time, all the time... she was with me all the time, all the time, } \\
\text { all the time. }\end{array}$ \\
\hline $\begin{array}{l}\text { - Special relationship } \\
\text { between child and } \\
\text { horse }\end{array}$ & $\begin{array}{l}\text { P2: ... it's really a relationship, really a friend. [...] It's, er... He's happy to see } \\
\text { him, he cuddles him, pets him, even during the therapy sessions, he lies on top } \\
\text { of him... [...] He has good chemistry... } \\
\text { P1: My husband, yesterday, I think, he was joking around 'So [child's name] } \\
\text { your horse, you're going to see Mr. Oui tomorrow?' I said: 'But [husband's } \\
\text { name], it's not Mr. Oui...' And he said: 'How come, what's the horse's name?' } \\
\text { He did it on purpose; I had [child's name] in my arms... And she says: 'Mmmm, } \\
\text { mmmm.... To say Mousse. She said the M, so [...] I think she has a good } \\
\text { relationship with Mousse to make the effort to try to say it. } \\
\text { P2: I think it could be another horse and he would love it just as much! } \\
\text { P3: When things were going well, she really established a contact with the }\end{array}$ \\
\hline
\end{tabular}




\begin{tabular}{|l|l|}
\hline \multirow{5}{*}{$\begin{array}{l}\text { animal. [...] At the beginning, she didn’t want anything to do with it and } \\
\text { afterwards, she started to pet him, there was an evolution but it has } \\
\text { deteriorated... } \\
\text { P3: To be close to a horse... it's like the entire relationship of the person with } \\
\text { the animal can be developed and it’s taking care of him too, brushing him and } \\
\text { she was working at the same time... [...] Feeding him at the end, er, as if to } \\
\text { thank him basically. } \\
\text { P4: Because by riding, he will definitely become aware of a horse and have to } \\
\text { pay attention and care for the horse, like a cat or a rabbit... Since at that... so, } \\
\text { er... at that level it's general, it's not specific to the horse. }\end{array}$} \\
$\begin{array}{l}\text { P1: We haven’t really got to that point, for her it’s really like... She needs the } \\
\text { basic skills to be able to... } \\
\text { P3: To dress himself, er... that sure would be good! Getting dressed alone he } \\
\text { can manage quite well. But er... I have to admit that socks are more difficult. He } \\
\text { has less strength, dexterity is more difficult for him. Eating too. I'd say that he } \\
\text { doesn’t know how to hold his utensils... But er... that wouldn’t be bad more } \\
\text { than that... [Are these things that you are working on in hippotherapy?] Er... no. }\end{array}$ \\
\hline
\end{tabular}


Appendix 1. Interview Guide

1. Tell me how you heard about hippotherapy?

2. Tell me about the motivations that triggered the process of looking for a follow up for your child in hippotherapy.

3. What brought you to consult to the rehabilitation clinic offering hippotherapy services?

a. How did you heard of it?

b. What is, according to you, hippotherapy?

c. Do you know of other approaches, like therapeutic horsebackriding?

d. Tell me about what you understand of one or these approaches?

e. What are, according to you, their similarities and differences?

4. From a general perspective, what do you think of hippotherapy?

- Positives aspects

- Inconveniences

5. More specifically, what do you think this means of rehabilitation will bring to your child?

6. What objectives would you like your child to reach with this means of rehabilitation?

- Gross and fine motor skills

- Balance

- Functional abilities: activities of daily living, play, etc.

- Communication

- Interpersonal relationship

- $\quad$ Others

7. According to you, what are the benefits and the inconveniences to be close to a horse?

\section{For parents of children currently receiving hippotherapy:}

8. How did those benefits and inconveniences changed since the beginning of the rehabilitation as compared to when you were on the waiting list?

9. Since the beginning of the therapy, what are the changes in your child that you attribute to receiving hippotherapy?

- $\quad$ Gross and fine motor skills

- Balance

- Functional abilities: activities of daily living, play, etc.

- Communication

- Interpersonal relationship

- $\quad$ Others

10. What is, according to you, your child's perception regarding hippotherapy?

11. How would you describe the relationship between your child and the horse? 